\title{
Gender assignment: whose decision is it?
}

\author{
Y A Arundathi Jayasena ${ }^{1}$, K S H de Silva ${ }^{2}$ \\ Sri Lanka Journal of Diabetes Endocrinology and Metabolism 2011; 1: 51-53
}

\section{Introduction}

Congenital adrenal hyperplasia $(\mathrm{CAH})$ is a group of autosomal recessive disorders which are attributed to be the commonest cause of virilization in a girl (1). 21 hydroxylase deficiency accounts for approximately $95 \%$ of CAH of which about $75 \%$ are of the salt losing type or classic CAH (2). Classic CAH patients suffer both aldosterone and cortisol insufficiency and present with salt wasting, failure to thrive and potentially fatal hypovolaemia and shock (3). The appearance of external genitalia in females depends on the degree of hyperandrogenism as well as on the severity of CYP21A2 allelic variation (2). Therefore $\mathrm{CAH}$ in a girl results in ambiguous genitalia which could be detected at birth but if complete virilization occurs, male gender assignment could result $(4,5)$. Male bias in choice of gender in certain populations might result in strong social pressures on families resulting in male gender assignment in extremely virilized girls with congenital adrenal hyperplasia (4). Once the true identity is known, changing the gender of patients is extremely difficult once assigned and is influenced by numerous social, cultural and medical aspects and will then result in immense psychological trauma to the child and family (5).

\section{Case report}

A 4-year and 9-month old boy, born to unrelated parents, was referred for further evaluation. He was the third living child of a family of five, where there had been one miscarriage and a death of a child with genital ambiguity whose details were not available.

He was born at term with a birth weight of $2.8 \mathrm{~kg}$. Genital ambiguity had been noted at birth with a $2.5 \mathrm{~cm}$ phallus, fused, rugose labioscrotal folds and no palpable gonads. He had been transferred to Lady Ridgeway Hospital (LRH) on the third day of life for management of possible salt losing congenital adrenal hyperplasia. On day 6 of life, he had developed features of adrenal crisis clinically and biochemically with 17 hydroxy progesterone (17-OHP) 145nmol/1. Initial management of salt losing congenital adrenal hyperplasia with intravenous hydrocortisone and oral fludrocortisone and fluid resuscitation was done and thereafter lifelong replacement of oral hydrocortisone and fludrocortisone commenced.
A buccal smear was arranged which suggested XX genotype with subsequent confirmation by karyotype as 46XX. Ultrasonically a uterus and vagina with a common urogenital sinus were seen. He was then referred back to the local hospital for follow up. By the review at 4 months of age, he had already been registered as a male despite counseling on several occasions.

He was re-referred back to Lady Ridgeway Hospital at 4 years and 9 months of age, by which time he was a well adjusted boy, the tallest in his class in nursery with a height of $110 \mathrm{~cm}$ (75th - 90th centile) and weighed $16 \mathrm{~kg}$ (25th centile). There was evidence of possible poor treatment or compliance as he was dark in complexion with pigmented palms and buccal mucosa with an advanced bone age of 10 to 11 years at a chronological age of 4 years and 9 months. His repeat 17-OHP was $>57.6$ $\mathrm{nmol} / \mathrm{l}$ and serum testosterone was $0.65 \mathrm{pg} / \mathrm{ml}(0.15-0.6)$. His hydrocortisone and fludrocortisone doses were optimized. Genitourinary endoscopy to assess the anatomy of genitourinary tract showed a uterine cavity, vagina and a urogenital sinus. Systemic examination was normal and blood pressure 100/70 mmHg.

Counseling of parents was done regarding the probable future implications of continuing as a male. The fact that fertility was possible only as a female was emphasized by the consultant paediatrician and consultant paediatric surgeon.

\section{Discussion}

Genital ambiguity in a genotypic female with features of mineralocorticoid insufficiency during the neonatal period and markedly elevated 17-OHP is suggestive of salt losing/classic CAH due to 21-hydroxylase deficiency (2). Definitive genetic diagnosis was not possible due to limited facilities. The child was reared as a boy for 4 years and 9 months which presented numerous problems in the management. The psychosocial implications of genital ambiguity were documented in literature, and include perceived incongruence between genital appearance and assigned gender by parents and society, conflicting gender typing by family members, increased stigmatization, impaired genital self image and impaired body image by short stature (6).

\footnotetext{
${ }^{1}$ Senior Registrar in Paediatric Endocrinology, Lady Ridgeway Hospital, Colombo, ${ }^{2}$ Consultant Paediatrician, Lady Ridgeway Hospital, Colombo and Senior Lecturer, Department of Paediatrics, Faculty of Medicine, Colombo, Sri Lanka.
} 


\section{Gender reassignment and surgical intervention}

This child was managed as classic CAHin a girl which was suspected at birth due to ambiguous genitalia. Despite counseling to delay the birth registration until karyotype was available, the parents registered the child as a boy. At this stage of presentation, reassignment of gender is very likely to result in significant psycho-emotional trauma as well as immense social repercussions to the child and the family. Breast development at puberty with 'menstruation' manifesting as bleeding per urethra are to be anticipated if continued to be brought up as a boy (5). Therefore to prevent the resultant psychological damage to some extent, he will need to undergo oophorectomy and hysterectomy which are irreversible surgical procedures. This child will have the possibility to retain fertility only if reared as a girl. If gender reassignment as a girl is done she will invariably need feminizing genitoplasty which involves several stepped surgeries such as clitoral reduction, labioscrotal reduction and vaginoplasty. These surgical interventions can help facilitate heterosexual relationships and conception if desired (2).

\section{Precocious puberty}

Inadequately controlled adrenal androgen production associated with poor compliance or under treatment would result in premature activation of the hypothalamo-pituitary-gonadal axis which leads to advanced skeletal age (7). This will give rise to secondary central precocious puberty which then results in breast development and cyclical bleeding $(5,7)$. Inhibition of the above process is possible to some extent with a gonadotrophin releasing hormone $(\mathrm{GnRH})$ analogue which is a planned option for our patient. Nevertheless suppressing androgen production by treatment with hydrocortisone could also help the innate female characteristics which are disadvantageous if the child continues to be a boy (5).

\section{Short stature}

Markedly advanced bone age will compromise final height potential and would be further reduced if precocious puberty was to occur. This will invariably result in the child being a short adult (7). However, suppression of puberty with a GnRH analogue would facilitate gaining more height.

In view of the above problems and decisions regarding gender reassignment the following management plans were agreed to after detailed discussion with the parents.

- Continue to bring up the child as a boy because at present he is a well adjusted boy with a male gender identity which was in keeping with the parents' wishes.
- Feminizing genitoplasty or the need of uterus and vagina is to be decided, depending on which gender the child identifies with, when he is old enough to understand the future implications and gender identity. Therefore not to perform any irreversible surgical procedures such as oophorectomy or hysterectomy until the patient is old enough to decide.

- At present 'hypospadias' is to be corrected as this could still be reversed in case if feminization is required.

- A GnRH analogue to suppress puberty when there is evidence of central precocious puberty until the above decisions are made.

- Testicular prostheses around the time of puberty and treatment with testosterone may have to be considered if he continues as a male.

The goal of gender assignment is to ensure the best possible quality of life for the patient and it is dependent on sexual identity, sexual function and possibility of fertility (8). Furthermore parents' making this decision has been strongly challenged by some patient advocacy groups and ethicists who believe that responsibility for this decision belongs, as a right, to the affected individual. In their view gender assignment and surgery should be deferred until such an age when the individual can make informed decisions (9).

Thus undoubtedly, there will be many challenges to be faced by the child and family in the future necessitating continued psychological support and counseling.

\section{References}

1. Hughes IA. Ambiguous genitalia. In: Brook CGD, Editor. Clinical Pediatric Endocrinology. London: Blackwell Science Ltd, 2005: 171-83.

2. Phyllis $\mathrm{W}$ et al. Congenital adrenal hyperplasia due to steroid 21-hydroxylase deficiency: an endocrine society clinical practice guidance. Journal of Clinical Endocrinology and Metabolism 2010; 95(9): 4133-60.

3. NNSIS 2009 National Newborn Screening Information System. Available at http://www2.uthscsa.edu/nnsis

4. Ozbey $\mathrm{H}$ et al. Gender assignment in female congenital adrenal hyperplasia: a difficult experience. British Journal of Urology International 2004; 94: 388-91.

5. de Silva KSH, Samarasinghe M. Who am I? Sri Lanka Journal of Child Health, 2005; 34: 20-2.

6. Meyer-Bahlburg HF. Gender assignment and reassignment intersexuality: controversies, data and guidelines for research. Advances in Experimental Medicine and Biology 2002; 511: 199-223. 
7. Soliman AT et al. Congenital adrenal hyperplasia complicated by central precocious puberty: linear growth during puberty and treatment with gonadotropin releasing hormone analogue. Metabolism 1997; 46: 513-17.

8. Houk CP, Lee PA. Approach to assigning gender in 46XX congenital adrenal hyperplasia with male external genitalia: replacing dogmatism with pragmatism. Journal of Clinical Endocrinology and Metabolism 2010; 95 (10): 4501-8.

9. Thomas DFM. Gender assignment: background and current controversies. British Journal of Urology International 2004; 93 (suppl 3): 47-50. 